\title{
Doses de potássio na produção e qualidade de sementes de alface
}

\author{
Cristiaini Kano ${ }^{1}$; Antonio Ismael Inácio Cardoso ${ }^{1}$; Andréa R O Higuti ${ }^{1}$; Roberto L Villas Bôas ${ }^{2}$
}

${ }^{1}$ UNESP-Dep ${ }^{\text {to }}$. Produção Vegetal, C. Postal 237, 18603-970 Botucatu-SP; E-mail: criskano@ hotmail.com

\begin{abstract}
RESUMO
Devido à falta de informações relacionadas à adubação em hortaliças cojo objetivo é a produção de sementes, em culturas em que ocorre um aumento no ciclo, nota-se a necessidade de se estudar a influência de doses de nutrientes que proporcionem aumento de produtividade e obtenção de sementes de melhor qualidade. Este trabalho teve o objetivo de avaliar o efeito de diferentes doses de adubo potássico na produção e qualidade de sementes de alface cultivar 'Verônica'. O delineamento experimental utilizado foi o de blocos casualizados, com cinco tratamentos $(0,0 ; 1,0 ; 1,5 ; 2,0$ e 2,5 g planta $^{-1}$ de $\mathrm{K}_{2} \mathrm{O}$ ) e seis repetições. Os dados foram submetidos à análise de variância e regressão. Pelos resultados obtidos pode-se concluir que as doses de $\mathrm{K}_{2} \mathrm{O}$ avaliadas resultaram em aumento linear na produção (massa e número) de sementes, mas não afetaram a qualidade fisiológica (germinação e vigor) das mesmas.
\end{abstract}

Palavras-chave: Lactuca sativa $\mathrm{L}$., adubação potássica, $\mathrm{K}_{2} \mathrm{O}$, germinação, vigor.

\begin{abstract}
Potassium rates in the lettuce seed production and quality

There exist a lack of information about the fertilization of vegetables where occurr an increase of the vegetative cycle, when the seeds production is the final purpose. The influence of potassium rates was evaluated in lettuce cultivar Verônica for yield and quality of seeds. The experiment was conducted in randomized complete blocks, with five treatments $\left(0,0 ; 1,0 ; 1,5 ; 2,0\right.$ e $2,5 \mathrm{~g}_{\text {plant }}{ }^{-1}$ of $\left.\mathrm{K}_{2} \mathrm{O}\right)$ and six replications. The data were submitted to the variance analysis and to the regression analysis. The $\mathrm{K}_{2} \mathrm{O}$ rates resulted in a linear increase in the seed yield (mass and number) but did not affect the seed quality.
\end{abstract}

Keywords: Lactuca sativa $\mathrm{L}$., potassium fertilization, $\mathrm{K}_{2} \mathrm{O}$, germination, vigor.

\section{(Recebido para publicação em 11 de novembro de 2005; aceito em 15 de agosto de 2006)}

$\mathrm{U}$ ma planta bem nutrida está em condições de produzir um maior número de sementes viáveis, o que evidencia a influência da nutrição na produção de sementes. No início da fase reprodutiva, a exigência nutricional para a maioria das espécies torna-se mais intensa, sendo mais crítica por ocasião da formação das sementes, quando considerável quantidade de nutrientes, como o potássio e o nitrogênio, é para elas translocada. A boa formação do embrião e do órgão de reserva, assim como sua composição química, depende da disponibilidade de nutrientes para a planta, consequentemente, irá influenciar o metabolismo e o vigor da semente (Carvalho \& Nakagawa, 2000).

É grande a importância do fornecimento adequado de nutrientes na produção de sementes, especialmente do potássio, que ao lado do nitrogênio, é um dos elementos mais extraídos pelas plantas. Em quantidades adequadas o potássio desempenha várias funções na planta: o controle da turgidez do tecido, a ativação de muitas enzimas envolvidas na respiração e fotossíntese, a abertura e fechamento de estômatos, o transporte de carboidratos, a transpiração, a resistência à geada, seca, salinidade e à doença, a resistência ao acamamento e a manutenção da qualidade dos produtos (Malavolta, 1980; Marschner, 1995; Davis et al., 1997). Sua deficiência ocasiona redução no crescimento e na formação da "cabeça" de alface.

Embora existam estudos sobre nutrição mineral e recomendações de adubação para o cultivo comercial de alface, raramente se encontram trabalhos que abordem os efeitos dos nutrientes na produção de sementes e, principalmente, na qualidade fisiológica das mesmas. Isso se torna importante, pois, quando se busca a produção de sementes de alface, ocorre um aumento no ciclo da planta. No entanto, a escassez de informações relacionadas às exigências nutricionais, pode impedir a obtenção de aumento de produtividade e de qualidade das sementes.

Harrington (1960), ao avaliar a germinação de sementes de alface, cenoura e de pimenta oriundas de plantas cultivadas sob severa deficiência de nutrientes, verificou que a deficiência de potássio ocasionou diminuição na produção de sementes e na porcentagem de sementes normais. No entanto,
Delouche (1980) ressalta que a resposta típica de plantas cultivadas em solo de baixa fertilidade é a redução na quantidade de sementes produzidas e não a sua qualidade.

Kano et al. (2004) testando o efeito de diferentes doses de fósforo $(0 ; 200$; 400 ; 600 e $800 \mathrm{~kg} \mathrm{ha}^{-1}$ de $\mathrm{P}_{2} \mathrm{O}_{5}$ ) na produção de sementes de alface obtiveram aumento na produção com o aumento das doses, ajustando a resposta ao modelo linear. Contudo os mesmos autores verificaram que essas doses de fósforo não influenciaram a qualidade das sementes de alface (Kano et al., 2005), resultado semelhante ao obtido por Soffer \& Smith (1974).

Quanto ao nitrogênio, Carvalho (1978), ao avaliar o efeito da adubação nitrogenada sobre a produção e qualidade de sementes de alface, verificou que esta não afetou a qualidade e a produção de sementes.

Devido à escassez de informações relacionadas às exigências nutricionais da cultura da alface para produção de sementes, o objetivo deste trabalho foi avaliar o efeito de doses de adubo potássico na produção e qualidade de sementes de alface. 


\section{MATERIAL E MÉTODOS}

Este trabalho foi desenvolvido na Fazenda Experimental São Manuel, localizada no município de São Manuel SP, pertencente à Faculdade de Ciências Agronômicas (FCA) da Universidade Estadual Paulista (UNESP), Campus de Botucatu/SP, localizada à latitude sul de $22^{\circ} 44^{\prime} 50$ ', longitude oeste de $48^{\circ} 34^{\prime} 00^{\prime \prime}$ e altitude de $750 \mathrm{~m}$.

As plantas foram conduzidas em estufas de $20 \mathrm{~m}$ de comprimento, $7 \mathrm{~m}$ de largura e 3,8m de altura, na parte mais alta e, um pé direito de 2,5 m.

O solo utilizado no experimento foi LATOSSOLO VERMELHO Distrófico Típico (Embrapa, 1999) com os seguintes resultados obtidos na análise química: $\mathrm{pH}\left(\mathrm{CaCl}_{2}\right)=4,0 ; \mathrm{P}_{\text {resina }}=2 \mathrm{mg} \mathrm{dm}^{-3}$; matéria orgânica $=2 \mathrm{~g} \mathrm{dm}^{-3} ; \mathrm{V} \%=11$; e os valores de $\mathrm{H}+\mathrm{Al} ; \mathrm{K}$; $\mathrm{Ca}$; $\mathrm{Mg}$; $\mathrm{SB}$ e CTC expressos em mmol $\mathrm{dm}^{-3}$ respectivamente de: $25 ; 1,2 ; 2,0 ; 1,0 ; 3,0$ e 28 . A análise granulamétrica desse solo indicou 761, 199 e $40 \mathrm{~g} \mathrm{~kg}^{-1}$ de areia, argila e silte, respectivamente.

A calagem foi realizada 30 dias antes do transplante das mudas, utilizando-se calcário de alta reatividade, de modo a elevar a saturação de bases a $80 \%$ e faixa de $\mathrm{pH}$ próxima de 6,0 , conforme a recomendação sugerida por Raij et al. (1996).

A adubação de plantio com nitrogênio e matéria orgânica também foi feita de acordo com a análise química do solo e conforme proposta de Raij et al. (1996), para a produção de "cabeça". Foram fornecidos $0,26 \mathrm{~g}_{\text {planta }}{ }^{-1}$ de $\mathrm{N}$ na forma de sulfato de amônio e $500 \mathrm{~g}$ planta $^{-1}$ de Biomix ${ }^{\hat{a}}$ como fonte de matéria orgânica. Quanto ao fósforo, utilizou-se uma dose $50 \%$ superior $(3,9 \mathrm{~g}$ planta-1 de $\mathrm{P}_{2} \mathrm{O}_{5}$ ) à recomendada devido ao aumento que ocorre no ciclo da alface. Este nutriente foi fornecido apenas no plantio, utilizando-se o superfosfato triplo como fonte.

A análise química do Biomix ${ }^{a}$ indicou valor de $\mathrm{pH}$ de 7,7 e os valores de $\mathrm{MO} ; \mathrm{N} ; \mathrm{P}_{2} \mathrm{O}_{5} ; \mathrm{K}_{2} \mathrm{O}$; $\mathrm{Ca} ; \mathrm{Mg}$ e de $\mathrm{S}$, expressos em $\%$, respectivamente de: 53 ; 1,$30 ; 0,90 ; 0,47 ; 6,80 ; 0,25$ e 0,34 . A relação $\mathrm{C} / \mathrm{N}$ foi de $23 / 1$ e a umidade do composto de $60 \%$.

Na adubação de cobertura foram fornecidos o nitrogênio e o potássio. A adubação de cobertura com nitrogênio foi feita com nitrato de cálcio $(0,19 \mathrm{~g}$ planta $^{-1}$ de $\mathrm{N}$ por aplicação) e realizada inicialmente aos 10, 18 e aos 24 dias após o transplante (DAT), conforme recomendação de Raij et al. (1996) para a produção de "cabeça". Após as plantas atingirem o ponto comercial (33DAT), continuou-se à aplicação semanal dessa mesma dose até a colheita das sementes (121 DAT), fornecendo um total de 3,5 g planta $^{-1}$ de $\mathrm{N}$ durante todo o ciclo da planta, parcelado em 18 vezes.

Quanto ao potássio, aplicou-se no plantio $1 \mathrm{~g}^{\text {planta }}{ }^{-1}$ de $\mathrm{K}_{2} \mathrm{O}$ (fonte: cloreto de potássio), exceto para o tratamento T1 - sem potássio, o que eqüivale a recomendação de Raij et al. (1996), $150 \mathrm{~kg} \mathrm{ha}^{-1}$, para o cultivo de alface para produção de "cabeça" com uma população de 150 mil plantas ha-1. Já em cobertura, o potássio (fonte: cloreto de potássio) foi fornecido em duas épocas (no ponto comercial para colheita da "cabeça", 33 DAT, e no início do florescimento, 84 DAT) da seguinte forma: $\mathrm{T} 1$ - sem potássio $\left(\mathrm{K}_{2} \mathrm{O}\right)$ no ponto comercial para colheita da "cabeça" (C) e início do florescimento (F); $\mathrm{T} 2$ - $1 \mathrm{~g}$ planta $^{-1}$ no $\mathrm{C}$ e sem fornecimento no F; T3 - 1 g planta $^{-1}$ no $\mathrm{C}$ e 0,5 g planta $^{-1}$ no F; T4 - 1 g planta $^{-1}$ no C e 1 g planta ${ }^{-1}$ no F; e T5 - 1 g planta $^{-1}$ no C e 1,5 $\mathrm{g} \mathrm{planta}^{-1}$ no $\mathrm{F}$.

O delineamento experimental utilizado foi blocos casualizados com cinco tratamentos (doses de $\mathrm{K}_{2} \mathrm{O}$ ) e seis repetições, com a unidade experimental composta por quatro plantas, as quais foram todas utilizadas para a obtenção das sementes. Os tratamentos foram obtidos somando-se a quantidade de $\mathrm{K}_{2} \mathrm{O}$ utilizado no plantio e em cobertura, resultando nas seguintes doses (tratamentos): 0,$0 ; 1,0 ; 1,5 ; 2,0$ e 2,5 g plan$\mathrm{ta}^{-1}$ de $\mathrm{K}_{2} \mathrm{O}$. O potássio em cobertura foi utilizado visando suprir as necessidades da cultura para semente, cujo ciclo é muito superior àquele para a produção de "cabeça", considerando-se duas etapas, uma vegetativa e outra reprodutiva.

Utilizou-se a cultivar de alface crespa 'Verônica' e a semeadura foi realizada no dia 17/02/04, em bandejas de poliestireno expandido de 128 células, contendo substrato comercial para hortaliças. Foram colocadas duas ou três sementes por célula, com posterior desbaste para uma planta por célula.
As mudas foram transplantadas em 24/03/04 para vasos de plástico com capacidade para 13 litros, sendo cultivada uma planta por vaso e totalizando seis linhas de vasos no sentido longitudinal da estufa, espaçadas de 1,0m e os vasos espaçados de $0,5 \mathrm{~m}$ entre plantas (centro a centro dos vasos).

As plantas foram tutoradas de modo a evitar o tombamento das mesmas na fase reprodutiva e a irrigação foi realizada através de gotejadores instalados individualmente nos vasos.

A colheita das sementes foi realizada manualmente na maturidade fisiológica, na fase de pêlos (papos) brancos sobre as inflorescências, conforme Reghin et al. (2000), com início aos 121 DAT e final aos 141 DAT. Assim que coletadas, as sementes foram avaliadas quanto à produção (massa e número de sementes por planta), massa de mil sementes e qualidade fisiológica (germinação e vigor) e mantidas em câmara seca $\left(20^{\circ} \mathrm{C} \mathrm{e} 40 \% \mathrm{UR}\right)$ para melhor conservação.

O teste padrão de germinação foi realizado conforme as Regras para Análise de Sementes (Brasil, 1992), com utilização de caixa gerbox em germinador a $20^{\circ} \mathrm{C}$. Para a primeira contagem foram consideradas as plântulas normais contabilizadas e retiradas aos quatro dias. A contagem final foi realizada aos sete dias, sendo consideradas germinadas as plântulas com o aparecimento das folhas cotiledonares. As avaliações foram diárias até o $7^{\circ}$ dia após a semeadura, para se obter, conforme Maguire (1962), o índice de velocidade de germinação das plântulas (IVG), que é um indicativo do vigor das sementes.

A qualidade das sementes também foi avaliada pela porcentagem de plântulas emergidas em bandejas de poliestireno expandido contendo substrato comercial, conforme metodologia adotada por Lima (2003), adaptada de Vieira \& Carvalho (1994). A escolha deste substrato ao invés do solo teve como finalidade simular o que ocorre na produção comercial de mudas de alface. Dessa forma, procurouse colocar as sementes em um teste que apresentasse as mesmas condições utilizadas comercialmente pelos produtores. Foram semeadas 50 sementes por repetição $(4 \times 50)$ para cada parcela e as bandejas foram mantidas em casa-de-vegetação 


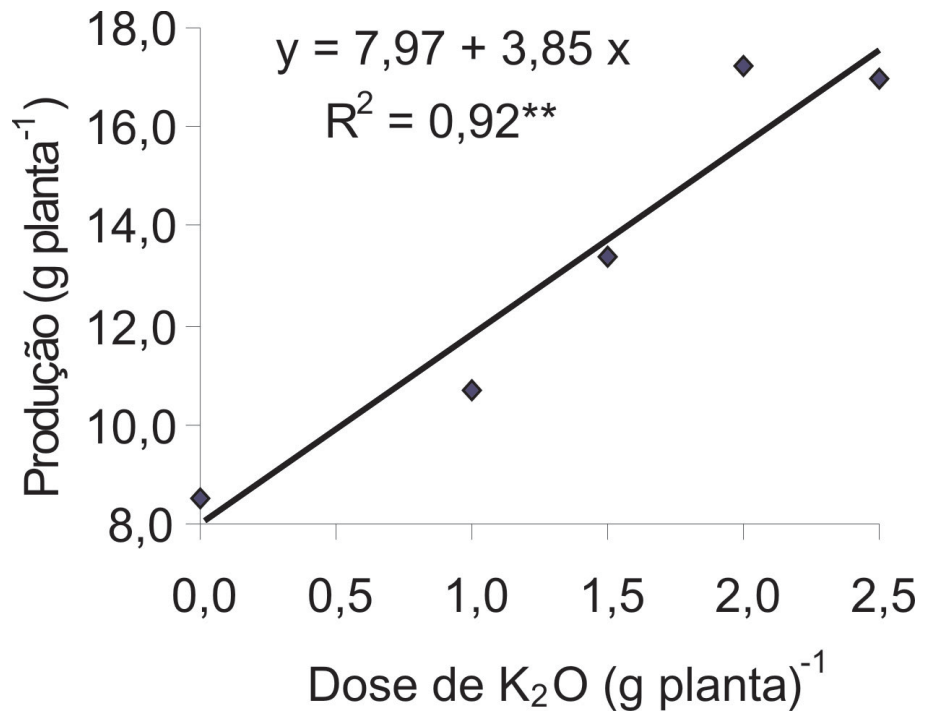

Figura 1. Produção de sementes de alface por planta em função de doses de $\mathrm{K}_{2} \mathrm{O}$. São Manuel, FCA/UNESP, 2004.

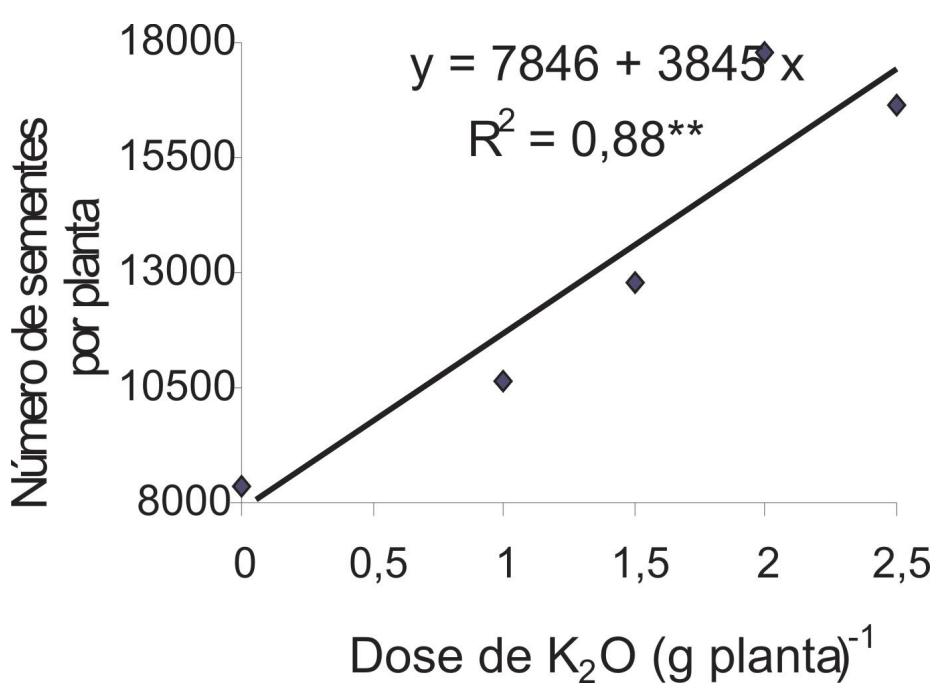

Figura 2. Número de sementes de alface por planta em função de doses de $\mathrm{K}_{2} \mathrm{O}$. São Manuel, FCA/UNESP, 2004.

durante as avaliações. As plântulas foram consideradas emergidas quando as folhas cotiledonares estavam totalmente abertas. As avaliações foram diárias, até o $10^{\circ}$ dia após a semeadura, para se obter o índice de velocidade de emergência das plântulas (IVE), conforme Maguire (1962).

Os resultados obtidos foram submetidos à análise de variância e em caso de efeito significativo, de acordo com o teste $\mathrm{F}$ para tratamentos, foi realizada a análise de regressão para verificar o efei- to de doses de potássio nas características avaliadas.

\section{RESULTADOS E DISCUSSÃO}

A produção de sementes, tanto em massa como em número, foi influenciada significativamente pelas doses de potássio. Os valores se ajustaram ao modelo linear, sendo que a cada aumento de $1,0 \mathrm{~g}$ planta $^{-1}$ de $\mathrm{K}_{2} \mathrm{O}$ fornecido, aumentou-se $3,85 \mathrm{~g}$ ou aproximadamen- te 3.845 sementes a mais por planta ( $\mathrm{Fi}$ guras 1 e 2).

Com apenas $2 \mathrm{~g}$ de $\mathrm{K}_{2} \mathrm{O}$ fornecido por planta, dobrou-se a produção de sementes em relação à testemunha (sem adição de potássio). Considerando-se o ajuste dos resultados ao modelo linear, doses mais elevadas de $\mathrm{K}_{2} \mathrm{O}$ podem proporcionar incremento na produção e no número de sementes. Kano et al. (2004) também relataram aumento linear na produção de sementes de alface 'Verônica' com aumento na dose de $\mathrm{P}_{2} \mathrm{O}_{5}$ (0 a $800 \mathrm{~kg} \mathrm{ha}^{-1}$ ), utilizando o mesmo solo deste experimento.

Ressalta-se que no início da fase reprodutiva, a exigência nutricional para a maioria das espécies torna-se mais intensa, sendo mais crítica por ocasião da formação das sementes, quando considerável quantidade de nutrientes, como o fósforo, o nitrogênio e o potássio é para elas translocada (Carvalho \& Nakagawa, 2000). Deste modo, a adubação com $\mathrm{K}_{2} \mathrm{O}$ nesta etapa mostrou ser tecnicamente vantajosa.

Constatou-se que a produção de sementes obtida neste trabalho foi superior a relatada por Viggiano (1990) para a cultivar Regina (3,86 g planta-1 $)$, por Kano et al. (2004) para a cultivar Verônica $\left(5,0 \mathrm{~g} \mathrm{planta}^{-1}\right)$ e superior que a maior produção obtida nos tratamentos avaliados por Izzeldin et al. (1980) que foi de $\left(10,5 \mathrm{~g}_{\text {planta-1 }}{ }^{-1}\right)$. Os valores também foram próximos da máxima produção obtida por Reghin et al. (2000), em experimento conduzido com a cultivar Verônica, que foi cerca de 18 g planta $^{-1}$ e também da produção média obtida por Carvalho (1978) para a cultivar crespa Gorga (20 g planta $\left.{ }^{-1}\right)$.

Quanto à qualidade das sementes, não houve efeito significativo de doses de potássio para todas as características avaliadas: massa de mil sementes, índice de velocidade de emergência, total de plântulas emergidas no $10^{\circ}$ dia após a semeadura em bandeja, primeira contagem do teste de germinação, germinação e índice de velocidade de germinação (Tabela 1).

Para massa de mil sementes obtevese uma média de $1,06 \mathrm{~g}$ (Tabela 1), valor superior ao relatado por Viggiano (1990), que obteve média de $0,83 \mathrm{~g}$, e semelhante ao máximo valor obtido por Reghin et al. (2000), que foi de 1,0 g para a cultivar Verônica, bem como ao valor médio 
obtido por Carvalho (1978) que foi de 1,09 g. O resultado obtido também esteve acima do intervalo citado por George (1999), que varia de 0,6 a 1,0 g, dependendo da cultivar de alface.

A germinação foi praticamente máxima em todos tratamentos (mínimo de 99\%) (Tabela 1), caracterizando a excelente qualidade das sementes obtidas. $\mathrm{Na}$ primeira contagem, os resultados obtidos (> 88\%) já indicavam o elevado vigor das sementes. Já para a emergência de plântulas aos 10 dias após a semeadura, entretanto, observou-se valores inferiores, cerca de 69\% (Tabela 1). Deve-se considerar que este teste foi realizado em condições de temperaturas elevadas (média de $33^{\circ} \mathrm{C}$ ) que podem ter induzido as sementes a uma dormência secundária. Segundo Viggiano (1990), sementes de alface podem ficar dormentes quando semeadas em substrato com temperaturas superiores à $30^{\circ} \mathrm{C}$. Esta possível indução de dormência também pode explicar os maiores valores de coeficiente de variação para as características avaliadas em substrato.

Kano et al. (2005) verificaram que doses crescentes de $\mathrm{P}_{2} \mathrm{O}_{5}$ também não afetaram a qualidade das sementes de alface da mesma cultivar avaliada no presente estudo. Soffer \& Smith (1974) também verificaram que o aumento no fornecimento de nutrientes no solo aumentou a produção de sementes de alface, mas não proporcionou correspondente aumento no vigor das mesmas.

De forma semelhante, em outras espécies a adubação potássica também não afetou a qualidade das sementes logo após a colheita, como pode ser observado em trabalhos de Rossetto et al. (1997) com canola, e de Costa et al. (1983) e Vieira et al. (1987) com soja.

Percebe-se que a planta de alface, como várias outras espécies, sob condições de estresse nutricional (baixas quantidades de potássio), reduz sua produção de sementes sem afetar a qualidade das mesmas, provavelmente visando à perpetuação da espécie com a produção de sementes de alta qualidade. Porém, a adubação com potássio após a formação da cabeça é altamente favorável para se obter elevados aumentos de produtividade.

Conclui-se que houve aumento linear na produção (massa e número) de se-

Tabela 1. Média dos resultados dos atributos de qualidade (germinação e vigor) das sementes de alface em cada tratamento. São Manuel, FCA/UNESP, 2004.

\begin{tabular}{|c|c|c|c|c|c|c|}
\hline \multirow{2}{*}{ 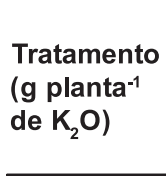 } & \multirow{2}{*}{$\begin{array}{c}\text { Massa de } \\
\text { mil } \\
\text { sementes } \\
\text { (g) }\end{array}$} & \multirow{2}{*}{ IVE } & \multirow{2}{*}{$\begin{array}{c}\% \text { de } \\
\text { plântulas } \\
\text { emergidas } \\
\text { no } 10^{\circ} \\
\text { DAS }\end{array}$} & \multicolumn{2}{|c|}{$\begin{array}{c}\text { Teste de germinação } \\
(\%)\end{array}$} & \multirow{2}{*}{ IVG } \\
\hline & & & & $\begin{array}{c}1^{a} \\
\text { contagem }\end{array}$ & $\begin{array}{l}\text { contagem } \\
\text { final }\end{array}$ & \\
\hline $\mathrm{T} 1(0,0)$ & 1,09 & 38,5 & 73,4 & 88 & 99 & 28,9 \\
\hline T2 $(1,0)$ & 1,07 & 39,9 & 72,3 & 89 & 99 & 27,7 \\
\hline T3 $(1,5)$ & 1,09 & 33,9 & 65,2 & 93 & 99 & 29,7 \\
\hline T4 $(2,0)$ & 1,02 & 32,5 & 60,9 & 88 & 99 & 27,3 \\
\hline T5 $(2,5)$ & 1,04 & 40,2 & 73,0 & 96 & 100 & 29,6 \\
\hline $\mathrm{F}$ & $0,90^{\text {ns }}$ & $0,64^{\text {ns }}$ & $0,66^{\mathrm{ns}}$ & $0,99^{\text {ns }}$ & $0,66^{\text {ns }}$ & $0,78^{\mathrm{ns}}$ \\
\hline C V (\%) & 7,5 & 20,8 & 17,1 & 9,1 & 0,4 & 10,8 \\
\hline
\end{tabular}

IVE= índice de velocidade de emergência; $\mathrm{DAS}=$ dias após a semeadura; IVG= índice de velocidade de germinação; ns= não significativo pelo teste $\mathrm{F}$ da análise de variância.

mentes com o aumento das doses de $\mathrm{K}_{2} \mathrm{O}$, enquanto a qualidade das sementes não foi afetada mesmo na ausência de adubação com $\mathrm{K}_{2} \mathrm{O}$.

\section{AGRADECIMENTOS}

A CAPES pela concessão da bolsa de doutorado à primeira autora e à FAPESP pelo auxílio financeiro (Processo 03/09637-0).

\section{REFERÊNCIAS}

BRASIL. Ministério da Agricultura e Reforma Agrária. 1992. Regras para análise de sementes. Brasília: SNDA/DNDV/CLAV. 365p.

CARVALHO JL. 1978. Efeito da adubação nitrogenada sobre a produção e qualidade de sementes de alface (Lactuca sativa L.). Piracicaba: USP-ESALQ. 54p. (Tese mestrado)

CARVALHO NM; NAKAGAWA J. 2000. Sementes: ciência, tecnologia e produção. Jaboticabal: FUNEP. 588p.

COSTA NP; FRANÇA NETO JB; ALMEIDA AMR; HENNING AA; PALHANO JB; SFREDO GJ. 1983. Efeito de níveis e métodos de aplicação de cloreto de potássio, sobre a germinação, vigor e emergência de sementes de soja. In: CONGRESSO BRASILEIRO DE SEMENTES. Campinas: ABRATES. p.114.

DAVIS RM; SUBBARAO KV; RAID RN; KURTZ EA. 1997. Compendium of lettuce diseases. California: Academic Press. 79p.

DELOUCHE JC. 1980. Environmental effects on seed development and seed quality. HortScience 15: 775-780.

EMPRESA BRASILEIRA DE PESQUISA AGROPECUÁRIA. 1999. Sistema brasileiro de classificação de solos. Brasília: EMBRAPA. 412p

GEORGE RAT. 1999. Vegetable seed production Italy: CABI Publishing. 328p.

HARRINGTON JF. 1960. Germination of seeds from carrot, lettuce, and pepper plants grown under severe nutrient deficiencies. Journal of Agricultural Science 30: 219-235.
IZZELDIN H; LIPPERT LF; TAKATORI FH. 1980. An influence of water stress at different growth stages on yield and quality of lettuce seed. Journal of American Society for Horticultural Science 105: 68-71.

KANOC; CARDOSOAII; VILLAS BÔAS RL. 2004. Doses de fósforo na produção de sementes de alface. Horticultura Brasileira 22: 410. (CD-ROM).

KANO C; CARDOSO AII; VILLAS BÔAS RL. 2005. Doses de fósforo na qualidade de sementes de alface. Horticultura Brasileira 23: 460.(CD-ROM).

LIMA MS; CARDOSO AII; VERDIAL MF. 2003. Plant spacing and pollen quantity on yield and quality of squash seed. Horticultura Brasileira 21: 443-447.

MAGUIRE JD. 1962. Speeds of germination-aid selection and evaluation for seedling emergence and vigor. Crop Science 2: 176-177.

MALAVOLTA E. 1980. Elementos de nutrição mineral de plantas. São Paulo: Agronômica Ceres. 251p.

MARSCHNER H. 1995. Mineral nutrition of higher plants. London: Academic Press. 889p.

RAIJ B; CANTARELLA H; QUAGGIO JA; FURLANI AMC. 1996. Recomendações de adubação e calagem para o Estado de São Paulo. Campinas: Instituto Agronômico \& Fundação IAC. 285p.

REGHIN MY; OTTO RF; ROCHA A. 2000. Indução do florescimento e produção de sementes de alface com diferentes doses de ácido giberélico. Horticultura Brasileira 18: 171-175.

ROSSETTO CAV; NAKAGAWA J; ROSOLEM CA. 1997. Efeito da adubação potássica e da época de colheita na qualidade fisiológica de sementes de canola (Brassica napus L. var. oleifera Metzg.). Revista Brasileira de Sementes 19: 349-354.

SOFFER H; SMITHOE. 1974. Studies on lettuce seed quality: V. Nutritional effects. Journal of American Society for Horticultural Science 99: 459-463.

VIEIRA RD; CARVALHO NM. 1994. Teste de vigor em sementes. Jaboticabal: Funep. 164p.

VIEIRA RD; SEDIYAMA T; CARVALHO NM; THIEBAUT JTL; SILVA RF; SEDIYAMA CS. 1987. Avaliação do efeito de doses de P e $\mathrm{K}$ na qualidade de sementes de soja. Revista Brasileira de Sementes 1: 83-89.

VIGGIANO J. 1990. Produção de sementes de alface. In: CASTELLANE PD, NICOLOSI WM, HASEGAWA M. (eds). Produção de sementes de hortaliças. Jaboticabal: Funep. p.1-13. 